\title{
MARKETING ESPORTIVO: UM ESTUDO DE CASO EM UMA EQUIPE DE FUTSAL
}

\author{
Lucas Cancian Pedroso ${ }^{1}$ \\ Fabrise De Oliveira Müiller ${ }^{2}$ \\ Yasmim Muraro Ragagnin ${ }^{3}$
}

\begin{abstract}
Resumo
O presente trabalho tem a finalidade de identificar as estratégias de marketing que propiciam visibilidade a um time de Futsal no Rio Grande do Sul. O estudo de caso foi realizado na Assoeva Futsal da cidade de Venâncio Aires. A pesquisa abordou os conceitos referentes ao marketing, os 4Ps, buscando mostrar a relação entre essas definições e as estratégias de marketing que o clube utiliza. A metodologia utilizada foi uma pesquisa qualitativa de cunho exploratório e a coleta de dados foi realizada por meio de entrevistas semiestruturadas. Os resultados demonstraram que as estratégias do Clube mais efetivas promoções para os jogos (descontos em ingressos antecipados), promoções em datas especiais. A divulgação em mídia espontânea da imprensa local ajuda a melhorar a visibilidade tanto da Assoeva quanto do esporte Futsal.
\end{abstract}

Palavras-chave: Futsal. Marketing. Estratégias de Marketing. 4 P's. Assoeva.

\begin{abstract}
The present work has a purpose of identification as a marketing strategy that provide visibility at Futsal time in Rio Grande do Sul. The case study carried out at Assoeva Futsal in the city of Venâncio Aires. One research deals with marketing concepts, the 4Ps, seeking to show a relationship between these activities and marketing strategy and the use of the club. A methodology used for qualitative study research and data collection was performed through semi-structured interviews. The results show that strategies are best sold for games (discounts on early tickets), promotions on special dates. Spontaneously publicizing the local press helps to improve the visibility of both the Association and Futsal sport.
\end{abstract}

Keywords: Futsal. Marketing. Marketing strategies. 4 P's. Assoeva.

\footnotetext{
${ }^{1}$ Graduando em Administração (Antonio Meneghetti Faculdade). E-mail: lucascancian6@gmail.com

${ }^{2}$ Doutora em Comunicação (UFSM), Mestre em Administração e Negócios pela PUC RS. Integrante do Grupo de Pesquisa Comunicação Institucional e Organizacional CNpq-UFSM. Email:fabrise.sma@terra.com.br.

${ }^{3}$ Graduanda em Administração (Antonio Meneghetti Faculdade). E-mail: yasmimrluiz@gmail.com.
} 


\section{Resumen}

El presente trabajo tiene la finalidad de identificar las estrategias de marketing que propician visibilidad a un equipo de Futsal en Rio Grande do Sul. El estudio de caso fue realizado en la Amateur Futsal de la ciudad de Venancio Aires. La encuesta abordó los conceptos referentes al marketing, los 4Ps, buscando mostrar la relación entre esas definiciones y las estrategias de marketing que el club utiliza. La metodología utilizada fue una investigación cualitativa de cuño exploratorio y la recolección de datos fue realizada por medio de entrevistas semiestructuradas. Los resultados demostraron que las estrategias del Club más efectivas promociones para los juegos (descuentos en boletos anticipados), promociones en fechas especiales. La divulgación en medios espontáneos de la prensa local ayuda a mejorar la visibilidad tanto de la Asociación y del deporte Futsal.

Palabras clave: Futsal. Marketing. Estrategias de Marketing. 4 P's. Añada.

\section{INTRODUÇÃO}

O presente trabalho tem como tema as estratégias de marketing de um clube de futsal que propiciam a visibilidade ao esporte. Por meio de um estudo de caso em uma equipe de futsal do Rio Grande do Sul, a Assoeva Futsal de Venâncio Aires, o objetivo proposto foi de analisar como o composto de marketing pode dar visibilidade ao esporte. O questionamento que norteia a pesquisa é: Quais são as estratégias de marketing de um time de futsal para a visibilidade do esporte?

O futsal é um dos cinco esportes mais populares no Brasil ${ }^{4}$, contudo, a diferença de número de torcedores, exibições na mídia e investimento em patrocínios parecem ser significativamente menores se comparados ao futebol de campo.

Considerando a relação entre a visibilidade e a importância dada ao futsal, versar sobre o marketing esportivo pode trazer respostas sobre o porquê de tal disparidade em relação ao futebol de campo, e mesmo a outros esportes, como vôlei, por exemplo. Para Pozzi (1998) o marketing esportivo e seu planejamento potencializam as possibilidades de atuação de times, marcas, profissionais, patrocinadores, etc.

O marketing esportivo está cada vez mais presente em nossas vidas, profissionalizando entidades esportivas, tornando possível a realização de eventos cada vez mais organizados, vendendo cada vez mais produtos ligados ao esporte, beneficiando a imagem de empresas e proporcionando o devido

\footnotetext{
${ }^{4}$ Informação disponível em: <http://esportes.r7.com/mais-esportes/fotos/brasil-nao-e-so-futebol-veja-osdez-esportes-mais-praticados-no-pais-16032014\#!/foto/1>. Acesso em: 04 out. 2016.
} 
suporte técnico e financeiro aos atletas, que tornam tudo isso possível (POZZI, 1998, p. 22).

Utilizando-se de entrevistas, o pesquisador buscou atender aos objetivos propostos e responder à pergunta de pesquisa. Com um roteiro semiestruturado foram entrevistados, o treinador da equipe, presidente, vice-presidente, patrocinador, um atleta, e um torcedor e, informações coletadas in loco no clube, que permitiram a estruturação da etapa de observação direta do trabalho.

\subsection{Marketing}

Segundo Meneghetti (2009), o marketing é forma de criar uma relação entre empresa e cliente que seja satisfatória para ambos os lados; Kotler e Keller (2006), afirmam que as pessoas e organizações envolvem-se em um grande número de atividades que poderiam ser chamadas de marketing, pois, este está por toda a parte, seja formal ou informalmente.

A atividade está se tornando uma peça cada vez mais indispensável para o sucesso, isso porque afeta profundamente a vida cotidiana, desde um site à, anúncios que vê no dia a dia na televisão, internet, outdoors, jornais, entre outros. O marketing envolve desejos, necessidades, clientes e satisfação. Ao observar as conceituações de marketing esportivo, os primórdios que esclarecem o que significa o termo não apresenta significativas diferenças.

Segundo Pozzi (1998), os maiores responsáveis pela popularização do marketing esportivo no mundo foram as indústrias de bebidas alcoólicas e de cigarros, que devido a proibição do Congresso Americano, não poderiam passar propagandas em determinados horários. E por isso, empresas como Camel e Marlboro que produzem cigarros, Fosters e Campari que produzem bebidas, iniciam um longo e bem-sucedido histórico de associação com o esporte, mais especificadamente o automobilismo.

Mas o marketing em grande escala começou a tomar forma na revolução industrial nos Estados Unidos ocorrida no final do século XIX. Após esse ocorrido o marketing começou a evoluir e foi dividido em três estágios sucessivos de seu desenvolvimento, isso se deve pelo modo de pensar das pessoas que iam mudando conforme os anos. Os estágios são segundo Etzel, Walker e Stanton, (2001), a orientação para produção, orientação para vendas e orientação para marketing, contudo mesmo muitas empresas terem evoluído para o terceiro estágio, algumas ainda ficaram 
no primeiro ou no segundo devido a seu modo de trabalho, ou escolha do seu dono etc., veremos agora cada um desses estágios.

Orientação para produção segundo Kotler e Keller (2006) afirmam que os clientes dão preferência a produtos de baixo custo e fáceis de se encontrar. Nas relações comerciais a orientação para produto é um dos conceitos mais antigos.

A orientação para as vendas ficou conhecida por uma grande dependência da pratica promocional, ou seja, os gestores das áreas de vendas usavam-se muito de promoções para vender seus produtos no mercado e ganhar algum diferencial da concorrência, esse estágio de orientação para as vendas foi bastante utilizado na década de 1950, quando a era da orientação para o marketing começou a nascer segundo Etzel, Walker e Stanton (2001).

Em meados da década de 1950 surgiu a orientação por marketing. Essa orientação que busca satisfazer as necessidades do cliente, ou seja, ao invés de produzir qualquer produto e tentar vender, primeiro foi analisado o que o cliente queria e assim foi produzido, foi uma pratica centrada no cliente. Para conseguir aplicar essa mudança nas empresas que era passar da orientação de vendas para a orientação para marketing as empresas enfrentavam três obstáculos quanto a implementação em relação aos seus colaboradores, que era uma resistência organizada, lentidão para aprender e rapidez para esquecer segundo Kotler e Keller (2006).

Essa mudança ocorreu segundo Etzel, Walker e Stanton, (2001), porque os consumidores tinham mudado após a $2^{\mathrm{a}}$ Guerra Mundial, eles estavam mais sofisticados, mais atualizados, outro fator foi que por causa da guerra muitas mulheres começaram a trabalhar, o que deixou o consumidor com mais conhecimento, menos ingênuos e menos influenciáveis, sem falar na enorme quantidade de oferta do mesmo produto.

Assim, considerando que predominam em empresas com o pensamento estratégico a orientação para o mercado, as estratégias se configuram em modos de fazer com que a organização atinja seus objetivos e metas. Em marketing, elas se darão por intermédio da atuação do gestor no composto formado por preço, produto, praça e promoção.

\subsection{Elementos da estratégia de marketing}


Mullin, Hardy e Sutton (2004), dizem que muitas organizações utilizaram estratégias fundamentais do plano de jogo de vários treinadores famosos, onde eles avaliam seu próprio talento, desenvolvem suas táticas e manuais de jogo após analisarem com cuidado seus oponentes, essa é a essência da estratégia que é levada do vestiário para a empresa do ramo esportivo. Essa estratégia precisa de uma análise continua do ambiente da empresa, para isso se estabelece metas a longo prazo e planos para que seja possível alcançar essas metas.

Hoje em dia, para um produto ter sucesso no mercado, seja ele um serviço, uma mercadoria, depende de uma estratégia de marketing eficaz. Mesmo que se crie um produto, considerado de qualidade, se os clientes não compreenderem as especificações e comunicações sobre o mesmo, existem reais possibilidade de fracasso, confirmam Bonne e Kurtz, (2009).

Por isso, um plano de marketing eficiente é aquele que alcança os seus clientes na hora certa, os convence a testar a sua mercadoria e desenvolve um contato com o público a longo prazo.

Bonne e Kurtz, (2009), assim como Kotler e Keller (2006) e Etzel, Walker e Stanton (2001), apresentam as estratégias de marketing a partir dos conceitos de preço, produto, praça e promoção. Para que se possa atuar com o mix referido, conhecer o mercado alvo de atuação da marca é questão prioritária.

Produto no marketing segundo Bonne, e Kurtz, (2009), é muito mais que só a mercadoria, o serviço ou a ideia, produto é um resumo amplo que inclui atender por completo as necessidades do cliente com relação a mercadoria, serviço ou ideia.

Por isso a estratégia de produto inclui decisões sobre design da embalagem, atendimento ao cliente, nomes de marcas, marcas registradas, patentes, garantias, ciclo de vida de produtos, seu posicionamento no mercado, desenvolvimento de novos produtos além de determinar quais mercadorias e serviços a empresa deverá oferecer a seu grupo de consumidores, seu mercado alvo, segundo Bonne, e Kurtz, (2009).

Segundo Bonne, e Kurtz, (2009) assim como Kotler e Keller (2006) e Etzel, Walker e Stanton, (2001), as estratégias para produtos são classificadas em Produtos industriais e Produtos de consumo. Os produtos industriais são produtos que contribuem para a saída de outros produtos para a revenda seja contribuindo de forma direta ou indiretamente. Os produtos industriais são divididos entre: Instalações, que tem esse nome devido a grandes investimentos de capital onde são investidos em maquinaria pesada para sistemas de telecomunicação ou construção novas fábricas. 
Quando se trata de produtos não se pode deixar de considerar a marca. Marca é nada mais nada menos que um sinal, um nome, termo, símbolo, design, que faz ligação do produto a empresa que o fabricou, e isso a diferencia dos concorrentes, muitas pessoas compram determinados produtos para ganharem status por causa de sua marca que é famosa no mundo, segundo Bonne, e Kurtz, (2009) assim como Kotler e Keller (2006) e Etzel, Walker e Stanton, (2001). Muitas empresas buscam fortalecer o nome da sua marca em seus produtos, pois com isso agregam um valor maior a ele segundo Bonne, e Kurtz, (2009) assim como Etzel, Walker e Stanton, (2001).

São as estratégias da praça que permite que os fabricantes cheguem aos consumidores com suas mercadorias na quantidade, hora e local certos. Na estratégia de distribuição, deve-se tomar as seguintes decisões, que são os meios de transporte, armazenagem, processamento de pedidos, controle de estoque e seleção de canais de marketing, que é um grupo de instituições chamadas de intermediários, que são os agentes, atacadistas, varejistas, representantes, que fazem, a passagem de mercadorias do fabricante ao consumidor final, segundo Bonne e Kurtz (2009).

A existência de intermediários entre o produtor ou fabricante e o consumidor deve agregar valor para o cliente, e a presença de mais ou menos intermediários sendo eles agentes, representantes, atacadistas e varejistas tem a ver com o tipo de produto ou serviço, Segundo Bonne e Kurtz (2009).

Canal de distribuição é um sistema organizado de pessoas e empresas envolvidas no envio de uma propriedade, produto ou serviço, durante a sua condução do produtor até o consumidor final ou usuário de negócios segundo Bonne, e Kurtz, (2009) assim como Etzel, Walker e Stanton, (2001).

Intermediário é uma empresa comercial (Agente, varejista, atacadista) que presta serviço que são relacionados diretamente com a aquisição ou venda de um produto, e a sua condução do produtor ao consumidor. Os intermediários são classificados em dois grupos: Intermediários comerciais e Agentes intermediários, os intermediários comerciais são os que tomam posse dos produtos que eles ajudam a vender, comercializar, são eles os atacadistas e os varejistas e os agentes intermediários como o próprio nome diz são as pessoas que não possuem os seus produtos, mas que saem para mostrar e vender os produtos, são eles os corretores imobiliários, representantes dos fabricantes e agentes de viagem de acordo com Etzel, Walker e Stanton, (2001).

A Promoção é o ato de informar, influenciar a decisão de compra, para isso se utiliza vários métodos para passar a mensagem sobre as mercadorias, serviços ou ideias, 
segundo Bonne e Kurtz, (2009), as mensagens podem ser transmitidas de duas maneiras: indiretamente por meio de promoções e propagandas, e diretamente por intermédio de vendedores.

Para se comunicar com seu mercado-alvo de maneira mais eficiente segundo Bonne e Kurtz, (2009), muitas organizações utilizam um meio chamado de Comunicações integradas de marketing (IMC em inglês), para dirigir todas as atividades promocionais para que o consumidor receba uma mensagem unificada e consistente.

A propaganda se divide em duas categorias: Propaganda de produto e Propaganda institucional, a propaganda de produto é a venda não pessoal de um bem ou serviço especifico, tem a intenção de atrair consumidores, e a propaganda institucional diferente da propaganda de produto, promove a imagem da empresa, organização, agência governamental, pessoa, indústria, localização geográfica, ou um conceito, ideia ou filosofia, segundo Bonne, e Kurtz, (2009).

A promoção de vendas é um estimulo para a compra mais rápida ou em maior quantidade, é um conjunto de ferramentas de incentivo ao consumidor e ao comércio segundo Bonne, e Kurtz, (2009) assim como Kotler e Keller (2006) e Etzel, Walker e Stanton, (2001).

Uma dessas ferramentas são as amostras, que é a tentativa de obter vendas futuras por meio de distribuição de produtos gratuitos, geralmente as amostras são distribuídas em demonstrações em lojas, eventos, incluídas em pacotes com outros produtos, pelo correio e de porta em porta, segundo Bonne, e Kurtz, (2009) assim como Kotler e Keller (2006) e Etzel, Walker e Stanton, (2001).

Segundo Bonne e Kurtz, (2009), preço é aquele fator onde se agrega valor ao produto, onde as empresas recebem o retorno de seu investimento. A estratégia de preços trabalha com as formas para estabelecer preços justificáveis e rentáveis, e esses preços estão sujeitos a avaliação pública, ou seja, são controlados pelo público, porque se coloca um preço muito acima do considerado normal, os consumidores não irão aderir aquele produto e optarão por um mais barato.

As estratégias de preço que as empresas adotam para determinar seu preço geralmente utilizam uma das duas estratégias de preço que são: Estratégia de desnatação, onde as empresas buscam um retorno rápido e assim seu preço inicial é maior, eles trabalham com consumidores menos sensíveis aos preços, geralmente são usadas em produtos novos no mercado, e isso se deve a quatro motivos: o primeiro de que teria um número suficiente de compradores que tem uma demanda alta, segundo 
que o custo unitário para produzir pequenos volumes de produtos não é alto e não tira a vantagem de se cobrar o que o mercado pode pagar, terceira que o preço alto do produto não atrairá concorrentes para o mercado, e quarta que utilizam para demonstrar qualidade no produto o seu preço alto segundo Bonne, e Kurtz, (2009) assim como Kotler e Keller (2006) e Etzel, Walker e Stanton, (2001).

A estratégia de penetração, que é utilizada no início do ciclo de vida do produto, utilizam o preço baixo para uma venda volumosa e para garantir uma fatia do mercado, trabalham com consumidores mais sensíveis a preço, existem três condições que ajudam a utilizar o preço baixo: a primeira é que o mercado é sensível ao preço e que com o preço baixo os consumidores irão comprar mais estimulando o crescimento; segundo que os custos para produzir o produto são baixos por produzir em grande quantidade; e terceiro porque o seu preço baixo não atrai concorrentes para seu mercado e desestimula os concorrentes atuais, Bonne, e Kurtz, (2009) assim como Kotler e Keller (2006) e Etzel, Walker e Stanton, (2001).

\section{ABORDAGEM METODOLÓGICA}

O presente estudo é uma pesquisa Qualitativa de cunho exploratório descritivo porque, segundo Gil (2002, p. 42) “[...] as pesquisas descritivas têm como objetivo primordial a descrição das características de determinada população ou fenômeno ou, então, o estabelecimento de relações entre variáveis.".

O estudo está delineado como um estudo de caso que segundo Yin (2010, p. 39) “O estudo de caso é uma investigação empírica que investiga um fenômeno contemporâneo em profundidade e em seu contexto de vida real, especialmente quando os limites entre o fenômeno e o contexto não são claramente evidentes".

\section{A Historia do Futsal e da Assoeva Futsal}

A História do futsal conhecido também como futebol de salão, segundo o site da Federação Gaúcha de Futsal ${ }^{5}$, relata que a origem do Futsal teve duas versões:

A Primeira foi que começou por volta de 1940 por pessoas da Associação Cristã de Moços (ACM), em São Paulo. O motivo foi que essas pessoas não conseguiam achar

\footnotetext{
${ }^{5}$ Federação Gaúcha de Futsal. Para mais informações: <http://www.fgfs.org.br/index.php/2015-08-01-2212-57/historia-do-futsal>. Acesso em: 23 abr. 2016. 
campos de futebol disponíveis para praticarem o esporte, e então começaram a jogar em quadras improvisadas como as de Basquete e as de Hóquei; chegavam a jogar com cinco, seis e até 7 jogadores em cada equipe no início, o que depois foi definido cinco jogadores em cada equipe, regra que se aplica até hoje.

O Futsal também foi chamado como "esporte da bola pesada", que devido ao material que ela era feita as bolas normais quicavam demais e saiam com muita facilidade da quadra de jogo, então seus tamanhos foram diminuídos e o seu peso foi aumentado.

A segunda versão é que o futsal foi inventado em 1934 pelo professor Juan Carlos Ceriani na Associação Cristã de Moços de Montevidéu, no Uruguai, e ele chamou este esporte de "Indoor-foot-ball", esta versão é a versão que se considera mais provável.

A história da Assoeva Futsal, que, segundo o site da Assoeva ${ }^{6}$, a Associação Esportiva de Venâncio Aires - ASSOEVA, foi fundada em 02 de Agosto de 1982, pelo Prof. Almedo Dettenborn. A sua fundação tinha objetivo de organizar as competições amadoras do Município, principalmente futebol de campo e futsal.

Em 2002, a Assoeva passou a competir como um clube no Campeonato Gaúcho de Futsal da terceira divisão, a Série Bronze, montando uma equipe com atletas locais. A equipe de Venâncio Aires disputou a competição até o ano de 2005.

Em 2006 a Assoeva estruturou uma parceria com a Universidade de Santa Cruz do Sul (Unisc), e essa parceria continua até os dias atuais. Naquele ano conseguiu ascender à Série Prata após a desistência de outra equipe.

De 2006 a 2008 a equipe disputou a Série Prata (segunda divisão) e desde 2009, o município de Venâncio Aires é representado pela Assoeva na Série Ouro (primeira divisão) do Futsal Gaúcho. Logo na sua estreia na elite do futsal gaúcho chegou até a final e acabou ficando com o vice-campeonato gaúcho, o que ocorreu também no ano seguinte. Em 2010, a ascensão da Assoeva continuou ingressando na Liga Nacional de Futsal (LNF).

Atualmente, a Assoeva está entre os melhores clubes do Brasil e, com sua equipe que está em franco crescimento e postula melhores colocações na Liga Nacional, além também de projetar o retorno a final do Campeonato Gaúcho de Futsal - Série Ouro. A atual diretoria aposta no trabalho de base com a categoria Sub-20.

\footnotetext{
${ }^{6}$ Assoeva. Para mais informações: <http://www.assoeva.com.br/historia>. Acesso em: 19 maio 2016. 


\subsection{Estudo de Caso e análise dos dados}

Para realização do presente estudo foram entrevistadas 6 pessoas: o presidente e o vice-presidente, um jogador, um patrocinador, o treinador e um torcedor do clube e foi realizada uma análise documental da clipagem ${ }^{7}$ do time do mês de junho de 2016.

As entrevistas foram gravadas e transcritas para uma posterior análise e a escolha do pesquisador foi baseada na disponibilidade dos entrevistados e nos poderiam contribuir para a pesquisa pela participação ou vivência no Clube.

O entrevistado 1 está na entidade desde 1989, onde já foi presidente em algumas oportunidades e, atualmente, é vice-presidente. O entrevistado 2 está no clube há sete meses, é um dos jogadores importantes do clube por ter participado vários anos na seleção brasileira de futsal. O entrevistado 3 sempre é torcedor, e, há aproximadamente três anos atrás, começou a se envolver mais com as atividades do clube sendo locutor dos jogos, apresentador das propagandas nos intervalos das partidas. Foi convidado para assumir a presidência, o que ocorreu este ano. O entrevistado 4 é um dos patrocinadores do clube, parceria que começou no ano de 2006 e que continua até hoje. O entrevistado 5, que acompanha o clube desde sua fundação. Em 2006 criou a famosa torcida febre amarela da Assoeva. Finalmente, o entrevistado 6 é o treinador da equipe e atua na Assoeva há 3 anos.

$\mathrm{Na}$ entrevista foi utilizado um roteiro semiestruturado elaborado pelo autor. $\mathrm{O}$ primeiro questionamento aos respondentes foi se tinham conhecimento da existência de um setor de marketing no clube. Esta pergunta foi pertinente, pois, atende o objetivo geral do estudo que é identificar como as estratégias de marketing em um time de futsal podem dar visibilidade ao esporte. O respondente 3, que é o presidente do clube afirmou que algumas ferramentas de marketing são executadas pelos próprios voluntários, ou seja, não existe um setor formalizado ou um profissional contratado para a atividade. Fica evidenciado que de acordo com o entrevistado, que responde pela maior liderança do clube, que o marketing se foca na venda de ingressos, venda de produtos (camisetas, cadernos), site. $\quad \mathrm{O}$ respondente admite que seria necessário profissionalizar. Isso

\footnotetext{
${ }^{7}$ O clipping ou clipagem é uma ferramenta estratégica de assessoria de imprensa. Refere-se ao monitoramento e seleção de notícias, independente do meio de comunicação. Para mais informações: <http://www.ferramentasfoca.com/2013/07/clipagem-ou-clipping-no-jornalismo.html>. Acesso em: 15 nov. 2016.
} 
está explícito na assertiva: "carecemos realmente de alguém profissional (...) voltado para o marketing da Assoeva (Entrevistado 3).

Ainda nesse questionamento, de acordo com o jogador do time, há um desconhecimento sobre a existência do setor, considerando que a responsabilidade é do supervisor. Conforme afirma, há um espaço, um quiosque na cidade de Venâncio Aires onde se comercializa os produtos e, em sua opinião, neste local se dá a propaganda. Ainda, para o respondente, os atletas também são responsáveis pela atividade, fazendo a divulgação em suas redes sociais.

O vice-presidente quando indagado sobre o setor, relatou que a atividade é desenvolvida pela direção do clube. Pode-se, então, inferir, que mesmo o clube tendo uma representatividade no Rio Grande do Sul e no Brasil, não investe em marketing de forma organizada e planejada. Além disso, parece haver um desconhecimento sobre as funções, ferramentas e estratégias de marketing.

A postura do clube pode colocar em risco a relação do mesmo com os públicos. Conforme Meneghetti (2009), o marketing é uma forma de criar relações entre clientes e empresa.

Essa assertiva é reforçada quando os participantes foram indagados sobre quais as ações de marketing são realizadas pela Assoeva. O entrevistado 1 disse que muitas das ações estão focadas no levantamento de recursos financeiros, como rifas, sorteios, ação entre amigos e vendas de patrocínios. Segundo ele "basicamente é isso aí, patrocinadores, planos de sócios e ações entre amigos" (Entrevistado 1).

Dando continuidade a entrevista, a pergunta foi se a Assoeva faz trabalhos de divulgação, vendas e como tenta se evidenciar enquanto marca de futsal. As respostas indicaram muitos aspectos financeiros. Para o presidente, isso se dá pela busca de patrocinadores, em campanhas para adesão de sócios torcedores e os contatos com a imprensa.

O entrevistado 2 corrobora a afirmação do presidente, citando os patrocinadores, ajuda de custos de órgãos públicos e a arrecadação de dinheiro em jogos. A assessoria de imprensa é apontada pelo representante do patrocinador, segundo o entrevistado 4, a mídia dá visibilidade e isso favorece os veículos comercialmente e em termos de imagem, o clube.

A Assoeva possui ampla visibilidade em um jornal local, a mídia espontânea é produzida pelos profissionais do veículo e sem custos para o time. A figura 1 mostra as 
publicações em que a Assoeva tem visibilidade (junho de 2016) no jornal Folha do Mate $^{8}$ de Venâncio Aires.

Figura 1 - Folha do Mate - junho 2016

\begin{tabular}{|c|c|c|c|c|}
\hline $\begin{array}{c}\text { Período }(01 \text { a } \\
30 / 06 / 2016)\end{array}$ & Reportagem - chamada reportagem & Pagina & Colunas & Editoria \\
\hline $01 / 06 / 2016$ & Assoeva terá 11 jogos em junho & 1 & 3 & Folha Esportes \\
\hline $02 / 06 / 2016$ & $\begin{array}{c}\text { Assoeva enfrenta a Assaf, em Santa Cruz/Hoje } \\
\text { tem Assaf x Assoeva, as 19h }\end{array}$ & 2 & 5 & $\begin{array}{l}\text { Capa e Folha } \\
\text { Esportes }\end{array}$ \\
\hline 03/06/2016 & $\begin{array}{l}\text { Sem piedade, Assoeva aplica goleada em clássico } \\
\text { regional/Ao Natural, Assoeva vence a Assaf }\end{array}$ & 2 & 6 & $\begin{array}{l}\text { Capa e Folha } \\
\text { Esportes }\end{array}$ \\
\hline $\begin{array}{l}04 / 06 / 2016 \text { e } \\
05 / 06 / 2016\end{array}$ & $\begin{array}{l}\text { Sem piedade, Assoeva aplica goleada em clássico } \\
\text { regional/Ao Natural, Assoeva vence a Assaf }\end{array}$ & 1 & 4 & Folha Esportes \\
\hline $07 / 06 / 2016$ & Assoeva 3 a 2 Atlântico. Show! & 1 & 4 & Folha Esportes \\
\hline $08 / 06 / 2016$ & Assoeva está em oitavo lugar & 1 & 3 & Folha Esportes \\
\hline $10 / 06 / 2016$ & $\begin{array}{l}\text { Liga Futsal chega na primeira metade da fase } \\
\text { classificatória }\end{array}$ & 1 & 5 & Folha Esportes \\
\hline $\begin{array}{c}11 / 06 / 2016 \text { e } \\
12 / 06 / 2016 \\
\end{array}$ & $\begin{array}{l}\text { Assoeva recebe o Marreco na rodada pela Liga } \\
\text { Futsal/Assoeva enfrenta o debutante. }\end{array}$ & 2 & 7 & $\begin{array}{l}\text { Capa e Folha } \\
\text { Esportes }\end{array}$ \\
\hline $14 / 06 / 2016$ & $\begin{array}{l}\text { Assoeva vence mais uma de goleada na Liga } \\
\text { Futsal/ Assoeva 'depena' o Marreco: 6x1 }\end{array}$ & 2 & 7 & $\begin{array}{l}\text { Capa e Folha } \\
\text { Esportes }\end{array}$ \\
\hline $15 / 06 / 2016$ & $\begin{array}{l}\text { Solidez defensiva é o trunfo da Assoeva contra o } \\
\text { Guaíba/ Assoeva aposta na defesa sólida }\end{array}$ & 2 & 7 & $\begin{array}{l}\text { Capa e Folha } \\
\text { Esportes }\end{array}$ \\
\hline $16 / 06 / 2016$ & $\begin{array}{l}\text { Agora são quatro vitórias da Assoeva na Série } \\
\text { Ouro/ Assoeva vence em Guaíba por } 6 \text { a } 3\end{array}$ & 2 & 6 & $\begin{array}{l}\text { Capa e Folha } \\
\text { Esportes }\end{array}$ \\
\hline $\begin{array}{l}18 / 06 / 2016 \text { e } \\
19 / 06 / 2016\end{array}$ & Alaf x Assoeva vai ser de 'arrepiar' & 1 & 5 & Folha Esportes \\
\hline $21 / 06 / 2016$ & $\begin{array}{l}\text { Assoeva volta a jogar como mandante pela Liga } \\
\text { Futsal/ Assoeva recebe o Guarapuava }\end{array}$ & 2 & 7 & $\begin{array}{l}\text { Capa e Folha } \\
\text { Esportes }\end{array}$ \\
\hline $22 / 06 / 2016$ & $\begin{array}{c}\text { Assoeva cai uma posição na classificação da Liga } \\
\text { Futsal/ Assoeva apenas empata em casa }\end{array}$ & 2 & 4 & $\begin{array}{l}\text { Capa e Folha } \\
\text { Esportes }\end{array}$ \\
\hline $24 / 06 / 2016$ & As atenções para a Série Ouro & 1 & 5 & Folha Esportes \\
\hline $\begin{array}{c}25 / 06 / 2016 \text { e } \\
26 / 06 / 2016 \\
\end{array}$ & $\begin{array}{c}\text { Assoeva enfrenta a ASTF pela Série Ouro de } \\
\text { Futsal / Assoeva tem pela frente a ASTF }\end{array}$ & 2 & 5 & $\begin{array}{l}\text { Capa e Folha } \\
\text { Esportes }\end{array}$ \\
\hline $28 / 06 / 2016$ & $\begin{array}{c}\text { Assoeva joga fora de casa pelo Estadual Série } \\
\text { Ouro / Para fechar o turno na liderança }\end{array}$ & 2 & 6 & $\begin{array}{l}\text { Capa e Folha } \\
\text { Esportes }\end{array}$ \\
\hline $29 / 06 / 2016$ & Assoeva fecha o turno na liderança & 1 & 5 & Folha Esportes \\
\hline $30 / 06 / 2016$ & Assoeva tem a melhor defesa & 1 & 5 & Folha Esportes \\
\hline
\end{tabular}

Fonte: Desenvolvido pelo autor.

\footnotetext{
${ }^{8}$ Para mais informações: http://www.folhadomate.com/ Acesso em: 15 nov. 2016.

Saber Humano-Revista Científica da Faculdade Antonio Meneghetti
} 
O quadro evidencia uma significativa participação, demonstrando que mesmo o clube não tem uma assessoria de imprensa contratada, os próprios veículos de comunicação se interessam pelas pautas que envolvem o time e seus jogadores.

Quando questionados sobre os pontos positivos desenvolvidos pelo clube em termos de marketing junto aos públicos, o torcedor integrante da pesquisa indicou o uso das redes sociais. Porém afirma que mesmo com a facilidade das redes sociais na internet, o clube já teve uma relação mais ampla de proximidade com os torcedores. "A gente fazia mais esse corpo a corpo (...) eu sou suspeito para falar porque eu acredito muito na comunicação, muito no marketing" (Entrevistado 5).

Também quando indagados se o clube precisa de mais ações de marketing o entrevistado 3 diz que o clube precisa sim de ações de marketing, que o clube tem uma dificuldade por ter um grupo reduzido de trabalho onde todos são voluntários. A Assoeva conforme fala o presidente precisaria de "um profissional remunerado que tivesse um percentual no retorno obtido, na venda de espaços, (...) de novos patrocínios, é algo que eu estou visualizando para mais adiante (...). (Entrevistado 3).

O entrevistado 5 relata que é só isso que falta, mas também diz que entende o lado da diretoria, porque na crise, a preocupação principal é o atleta, ou seja, não atrasar o pagamento do jogador e da comissão técnica, “em função do pouco investimento que se tem no futsal, (...) acaba não sobrando para investir no marketing” (Entrevistado 5). O entrevistado 2 concorda que é preciso de mais ações, porque como ele diz que Venâncio Aires é uma cidade valoriza o esporte futsal.

\section{CONSIDERAÇÕES FINAIS}

O clube realiza algumas estratégias de marketing, mas parece desconhecer o que realmente é marketing, e que as ações que realiza em sua maioria são voltadas a promoções para jogos, e para vendas de ingressos. Existe um ótimo relacionamento do clube com a imprensa local (radio e jornal), com matérias diárias informando sobre os resultados datas de jogos, etc.

Respondendo ao problema de pesquisa percebeu-se que a Assoeva não faz ações de marketing especificas para divulgar o esporte, mas as ações de marketing que ela realiza para divulgar o clube, e seu bom relacionamento com as mídias locais contribuem para uma divulgação do esporte na região. 
O objetivo geral proposto que é "identificar como as estratégias de marketing em um time de futsal podem dar visibilidade ao esporte. " foi atingido. Percebeu-se que as estratégias que o clube utiliza como promoções para os jogos, promoções em datas especiais, rifas, ações entre amigos, promovem uma boa aproximação entre clube e torcedor e ajudam a melhorar a visibilidade da Assoeva.

A divulgação em mídia espontânea da imprensa local ajuda a melhorar a visibilidade tanto da Assoeva quanto do Futsal, ainda assim, poderia ser melhor explorada a questão da divulgação em jornais estaduais, melhorando assim a divulgação do clube e do esporte.

Quanto à promoção, percebeu-se que eles realizam diversas ações: em datas como dia dos namorados são feitas algumas promoções, rifas, ações entre amigos. O clube utiliza muito bem as relações públicas, especificadamente, na relação com a imprensa local, onde a mesma divulga o clube. Outra forma de divulgação do clube é o marketing que eles fazem com os jogadores nas redes sociais, chamando os torcedores para os jogos e também, com a página do clube nas redes sociais.

\section{REFERÊNCIAS}

ASSOCIAÇÃO Carlos Barbosa de Futsal. Uma História de Paixão e Conquistas. [S.l.]: ACBF, [2015?]. Disponível em: <http://www.acbf.com.br/pt/oclube/historia>. Acesso em: 18 out. 2016.

ASSOEVA Futsal. Página do Facebook. Disponível em: 〈https://goo.gl/kurpVU〉. Acesso em: 09 nov. 2016.

BONNE, Louis E.; KURTZ, David L. Marketing Contemporâneo. São Paulo: Cengage Learning, 2009.

BRASIL, Arnaldo. Trade Marketing: Introdução e Fundamentos. [S.1.]: Prime Action Consulting, 2010. Disponível em:

<http://www.primeaction.com/artigo/trade_marketing_introducao_e_fundamentos>. Acesso em: 29 set. 2016.

ETZEL, Michael K.; WALKER, Bruce J.; STANTON, William J. Marketing. São Paulo: Makron Books, 2001.

FEDERAÇÃO Gaúcha de Futebol de Salão (FGFS). História do Futsal. [S.1.]: FGFS, 2016. Disponível em: <http://www.fgfs.org.br/index.php/2015-08-01-22-12-57/historiado-futsal>. Acesso em: 23 abr. 2016.

GIL, Antônio Carlos. Como elaborar projetos de pesquisa. 4. ed. São Paulo: Atlas, 2002. 
KOTLER, Philip.; KELLER, Kevin Lane. Administração de marketing. São Paulo: Pearson Prentice Hall, 2006.

MENEGHETTI, Antonio. Aprendiz Líder. São Paulo: FOIL, 2009.

MULLIN, Bernard J.; HARDY, Stephen; SUTTON, Willian A. Marketing Esportivo. Porto Alegre: Artmed/Bookman, 2004.

PINHEIRO, Amilton. As marcas no esporte. [S.1.]: CECOM. Disponível em: $<$ http://portaldacomunicacao.uol.com.br/graficas-livros/65/artigo291141-3.asp>. Acesso em: 27 jun. 2016.

PITTS, Brenda G.; STOTLAR, David K. Fundamentos de marketing esportivo. São Paulo: Phorte, 2002.

POZZI, Luis Fernando. A grande jogada: teoria e prática de marketing esportivo. São Paulo: Globo, 1998.

RAUBER, João Francisco. Análise do nível de Satisfação do Público presente nos jogos da Assoeva. (TCC - Trabalho de Conclusão de Curso) Santa Cruz do Sul, UNISC 2009.

RODRIGUES, Mário. Preço e valor: qual a diferença? [S.1.]: O Portal da Administração, 2013. Disponível em:

$<$ http://www.administradores.com.br/noticias/negocios/preco-e-valor-qual-adiferenca/81065>. Acesso em: 25 out. 2016.

YIN, R. K. Estudo de caso: planejamento e métodos. Porto Alegre: Bookman, 2010. 